\title{
PAULO FREIRE E O DESENVOLVIMENTO DA AUTONOMIA NO ENSINO MÉDIO INTEGRADO DO IFSUL: CONTRIBUIÇÕES DA EDUCAÇÃO FÍSICA
}

\author{
Fabiana Celente Montiel \\ Instituto Federal Sul-rio-grandense (IFSul), Pelotas, Rio Grande do Sul, Brasil \\ AdRIANO JOSÉ ROSSETTO JúNIOR \\ Instituto Esporte \& Educação (IEE), São Paulo, Brasil \\ Danielle Müller de ANDRAde \\ Instituto Federal Sul-rio-grandense (IFSul), Pelotas, Rio Grande do Sul, Brasil \\ MARIÂNGELA DA Rosa AFONSO \\ Universidade Federal de Pelotas (UFPel), Pelotas, Rio Grande do Sul, Brasil
}

\begin{abstract}
Resumo: O estudo objetivou, a partir do pensamento de Paulo Freire, compreender as possibilidades de desenvolvimento da autonomia nas aulas regulares de Educação Física do Ensino Médio Integrado do Instituto Federal Sul-rio-grandense. Foram entrevistados/as 13 professores/as de Educação Física, com vínculo institucional entre seis e 15 anos. Recorreu-se à Análise Textual Discursiva, com suporte do NVivo, para a análise dos dados. Foram identificados elementos que sinalizam a presença de desenvolvimento da autonomia nas aulas regulares de Educação Física no Ensino Médio Integrado, via estímulo ao compartilhamento dos conhecimentos, à reflexão crítica e à tomada de decisão, evidenciando a potencialidade da Educação Física para a formação de pessoas críticas e participativas na Educação Profissional Técnica de Nível Médio.
\end{abstract}

Palavras-chave: Ensino Médio. Educação Profissionalizante. Educação Física. Autonomia.

\section{INTRODUÇÃO}

O Instituto Federal de Educação, Ciência e Tecnologia Sul-rio-grandense (IFSul) é um dos 38 institutos que compõem a Rede Federal de Educação Profissional, Científica e Tecnológica do Brasil, cujo compromisso social é ofertar educação profissional pública, gratuita e de excelência para a população (CONIF, 2019). O IFSul é composto atualmente por 12 campi, dois campi avançados e uma sede administrativa, estando, esta última localizada na cidade de Pelotas, no Rio Grande do Sul (RS).

De acordo com o Projeto Pedagógico Institucional (PPI), o IFSul tem como missão "[i]mplementar processos educativos, públicos e gratuitos de ensino, pesquisa e extensão, que possibilitem a formação integral mediante o conhecimento humanístico, científico e tecnológico e que ampliem as possibilidades de inclusão e desenvolvimento 
social" (IFSUL, 2015, p. 14), assumindo como função social a formação do ser humano crítico e solidário, compromissado com uma sociedade mais justa.

Essa função social enunciada pelo IFSul no seu PPI coaduna com o disposto na Lei de Diretrizes e Bases da Educação Nacional - LDB (BRASIL, 1996), a qual preconiza que a Educação Profissional Técnica de Nível Médio (EPTNM), atendendo a formação geral do/a educando/a, poderá prepará-lo/a para o exercício das formações técnicas. Entre as finalidades do Ensino Médio (EM), dispostas na LDB, está o "aprimoramento do educando como pessoa humana, incluindo a formação ética e o desenvolvimento da autonomia intelectual e do pensamento crítico" (BRASIL, 1996, s.p.). Nesse sentido, para além da formação técnica, está a formação integral do/a aluno/a.

Formação integral, neste artigo, é entendida como uma educação voltada à educação do/a jovem para a cidadania, considerando aspectos socioemocionais, físicos e cognitivos, cujo desenvolvimento dos conteúdos propostos se dá nas dimensões atitudinal, social, procedimental e conceitual, de modo a contribuir para que os/as educandos/as tornem-se seres humanos atuantes na sociedade em que estão inseridos, na perspectiva do ser mais (FREIRE, 2011b). Ciavatta (2015), ao discutir sobre a educação integral, sinaliza que esta deve garantir ao/à aluno/a o direito a uma formação completa com vista à ampliação da leitura do mundo e ao exercício da cidadania

Ao nos referirmos à formação cidadã, destacamos a necessidade do desenvolvimento da autonomia que, como preconizou Freire (1996; 2011b), diz respeito à libertação, ou seja, a superação da relação opressor/a-oprimido/a por meio de ações transformadoras da realidade.

Autonomia para Freire (1996) funda-se na ação-reflexão-ação sobre o mundo para transformá-lo. Na educação ela se efetiva a partir de vivências no cotidiano escolar, que sejam pautadas pela valorização e reconhecimento dos saberes dos/as alunos/as, bem como de suas trajetórias de vida. Pitano e Ghiggi (2010, p. 90-91) sinalizam que Freire

[...] fala da autonomia pela via da conscientização. Na relação de aprendizagem, pensamos, o autor não descarta, na perspectiva da formação para a autonomia, dimensões como educando ativo, mediação pelo diálogo, mudança das atividades relacionadas com o conteúdo que tenha como ponto de partida a própria realidade cultural do educando etc. Em particular, o diálogo, sendo uma exigência existencial, é uma relação de criação que educador, educadora, educando e educanda produzem. Educando, na criação dialógica, encontra-se a caminho da formação para a autonomia. É, o diálogo, a condição de possibilidade para a problematização do senso comum, das ingenuidades, tanto do educando quanto do educador, cuja superação permitem-lhe situar-se no mundo de forma autônoma, mas com os outros.

De acordo com Freire (1996; 2011a; 2011b; 2018), para a constituição de um ser humano autônomo, é preciso libertação, entendida como a práxis dos sujeitos sobre o 
mundo para transformá-lo. É no sentido da libertação que Freire evidencia a educação transformadora como via para o desenvolvimento da consciência crítica, individual e coletiva.

Ao propor uma educação problematizadora, Freire (2011b) defende a superação da alienação, ou seja, a transposição de uma educação que opera como se os/as alunos/as fossem meros depósitos do conhecimento. Portanto, para Freire (2011b), a educação problematizadora estimula, por meio de práticas libertadoras, que os/as educandos/as reconheçam-se como sujeitos dos processos de ensino e de aprendizagem, bem como compreendam suas razões de ser e de estar no mundo e assumam uma postura crítica, de modo a intervir na realidade para transformá-la.

Freire $(1996$, p. 121) sustenta que a prática que se aproxima da pedagogia da autonomia "tem que estar centrada em experiências estimuladoras da decisão e da responsabilidade", ou seja, são práticas em que os/as alunos/as sentem-se co-partícipes do processo educativo, de forma ativa e crítica, opinando e discutindo suas ideias com os/as demais participantes, colegas e/ou professor/a.

No âmbito da Educação Física (EF) e do esporte escolar, o desenvolvimento da autonomia se dá na:

[...] valorização do processo de ensino e aprendizagem de conteúdos esportivos que levem as crianças e jovens a desenvolverem competências e habilidades para a prática esportiva analisando e contextualizando a imposição externa, seja midiática, política, cultural ou social (ROSSETTO JÚNIOR, 2015, p. 41).

Soares et al. (1992) destacam que a EF na escola, ao objetivar a reflexão sobre a cultura corporal, contribui para a valorização das demandas dos interesses dos sujeitos de camadas populares, pois confronta questões como solidariedade e individualismo, cooperação e competição, distribuição e apropriação, negando a dominação e a submissão.

Diversos/as autores/as destacam a potencialidade da EF para a formação integral do ser humano, compreendido como uma totalidade, e sugerem que a EF promova atividades pedagógicas voltadas para o desenvolvimento de todas as dimensões do indivíduo, por meio de processos pedagógicos que contemplem todas as dimensões dos conteúdos (MONTIEL; SILVA, 2014; MONTIEL; PORTO, 2016; SOBRINHO; AZEVEDO; STEFANUTO, 2018).

Diante do exposto, consideramos que as aulas de EF na EPTNM, em especial na modalidade integrada, onde se dá sua maior inserção, devem promover e estimular o desenvolvimento da autonomia do/a educando/a, tal como disposto na LDB. A EPTNM é dividida em três modalidades de ensino: concomitante, subsequente e integrada. Neste artigo nos referiremos à modalidade integrada da EPTNM como Ensino Médio Integrado (EMI), pois é a forma usualmente utilizada para referir-se a essa modalidade dentro dos Institutos Federais. Portanto, objetivamos compreender as possibilidades de desenvolvimento da autonomia nas aulas regulares de EF no EMI do IFSul. 


\section{DECISÕES METODOLÓGICAS}

Este estudo faz parte de uma investigação maior, em nível de doutorado, que teve como foco analisar a contribuição das aulas de EF do IFSul para o desenvolvimento da autonomia do/a educando/a (MONTIEL, 2019). A pesquisa foi aprovada pelo Comitê de Ética em Pesquisa com Seres Humanos da Escola Superior de Educação Física, da Universidade Federal de Pelotas - RS, sob parecer 2757758. Trata-se de um estudo qualitativo, do tipo estudo de caso, que buscou a compreensão de um fenômeno, tendo como foco a qualidade do objeto observado (YIN, 2010; BICUDO, 2011).

A compreensão sobre as possibilidades de desenvolvimento da autonomia dos/as educandos/as, nas aulas de EF do IFSul é um fenômeno de ordem pessoal, organizacional, social e política, em que os limites entre o fenômeno estudado e o contexto não estão claramente definidos, não sendo possível isolar a compreensão dos/as professores/as do contexto social, político e cultural em que estão inseridos/as.

O IFSul possui atualmente um quadro de 41 professores/as de EF. Desses, 35 são efetivos/as e seis são substitutos/as, distribuídos/as nos diferentes campi da Instituição: Bagé (2), Camaquã (2), Charqueadas (2), Gravataí (1), Jaguarão (1), Lajeado (1), Novo Hamburgo (1), Pelotas (13), Pelotas Visconde da Graça (4), Santana do Livramento (1), Sapiranga (1), Sapucaia do Sul (4) e Venâncio Aires (2).

Participaram deste estudo 13 professores/as efetivos/as de EF que, para preservação de suas identidades, tiveram seus nomes substituídos por Alice, Augusto, Caio, Elias, Flora, Helena, Heitor, Igor, lan, Luiz, Marcos, Manoel e Pedro. Esses/essas docentes, no momento da pesquisa, encontravam-se nos anos intermediários de atuação (entre 6-15 anos), conforme sugerem Isaia e Bolzan (2008) para professores/as universitários/as. Optamos por tal classificação por entendermos que as carreiras do Ensino Básico, Técnico e Tecnológico (EBTT) e do ensino superior apresentam elementos comuns (MORAIS; HENRIQUE, 2014; BRITO; CALDAS, 2016; SILVA; MELO, 2018).

A delimitação dos/as professores/as investigados/as se deu pelo fato de já terem passado pelo período de adaptação à Instituição e terem consolidadas suas escolhas pedagógicas. Estão mais familiarizados/as com os diferentes processos e procedimentos institucionais, os quais fazem parte da dinâmica educativa da Instituição (ISAIA; BOLZAN, 2008).

Para a coleta das informações, foram realizadas entrevistas semiestruturadas, no segundo semestre de 2018. Elas foram gravadas, transcritas e enviadas aos/às professores/as para validação. Entre os temas que nortearam a entrevista semiestruturada, assinalamos: 1) objetivos da EF no EMI do IFSul; 2) objetivos/expectativas em relação aos/às alunos/as; 3) compreensão de autonomia; 4) possibilidades do desenvolvimento da autonomia dos/as alunos/as nas aulas de EF.

Os dados foram analisados por meio da metodologia de Análise Textual Discursiva - ATD, proposta por Moraes e Galiazzi (2011). A ATD é uma metodologia de análise que, ao transitar entre a análise de conteúdo e análise de discurso, promove a compreensão do que se busca investigar tendo a escrita como movimento de produção do conhecimento e da reconstrução da realidade. A análise teve como suporte técnico o 
programa NVivo 12, um software utilizado em pesquisas qualitativas que auxilia o/a pesquisador/a na organização e sistematização das informações, contribuindo, junto à ATD, para o alcance de resultados efetivos.

Seguindo os procedimentos da ATD, a análise dos dados foi realizada de acordo com as seguintes etapas: 1) leitura das entrevistas; 2) unitarização das entrevistas; 3 ) construção das categorias iniciais, intermediárias e finais; 4) escrita e interpretação dos resultados resultantes das categorias finais: conhecimento e informação; reflexão crítica; tomada de decisão. A Figura 1, a seguir, representa o percurso metodológico realizado neste estudo.

Figura 1 - Esquema do percurso metodológico

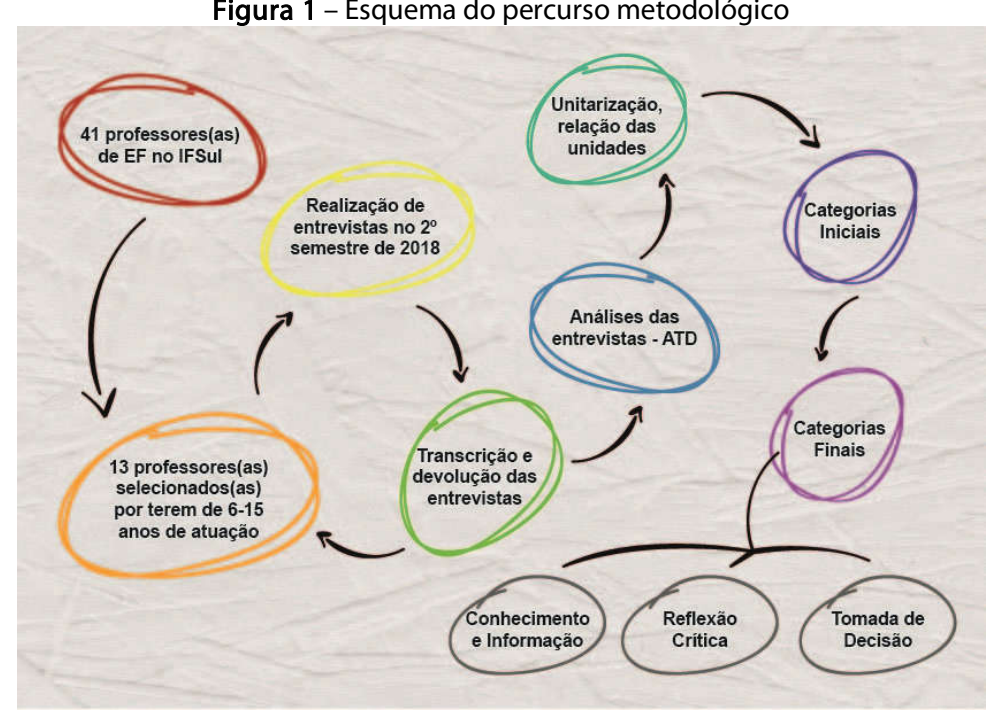

Fonte: Elaborada pelos/as autores/as (2019).

\section{DISCUSSÃO DOS RESULTADOS}

Os dados produzidos revelaram a potencialidade das aulas de EF para o desenvolvimento da autonomia do/a educando/a. De forma unânime os/as professores/as entrevistados/as manifestaram a ciência da contribuição da EF para a formação de sujeitos autônomos. Dessa forma, as categorias de análise, em consonância com os pressupostos freirianos, buscaram favorecer a compreensão acerca das possibilidades do desenvolvimento da autonomia do/a educando/a nas aulas de EF no EMI.

O desenvolvimento da autonomia demanda do/a educando/a, como primeira necessidade, dispor de informações e ser capaz de produzir conhecimentos gerando uma leitura correta de seu estar no mundo. Também pressupõe o desenvolvimento da capacidade de reflexão crítica, a qual envolve combinar diferentes elementos da realidade global, perceber as correlações que fazem com que cada aspecto da nossa 
vida privada esteja entrelaçado ao contexto social, político e econômico. A capacidade de reflexão crítica requer a percepção dos interesses de grupos particulares, que muitas vezes se ocultam como se fossem interesses que pudessem ser defendidos por toda a sociedade. Outro aspecto fundamental da autonomia é o desenvolvimento da capacidade de, com base no conhecimento socialmente produzido e na reflexão crítica, tomar decisões diante dos contextos concretos do cotidiano, com vistas ao direcionamento da existência pessoal e social a um sentido conscientemente escolhido (FREIRE, 1996; 2011a; 2011b; 2018).

Essa concepção de autonomia foi a que orientou a construção das seguintes categorias finais: conhecimento e informação, reflexão crítica e tomada de decisão. A seguir, discutiremos cada uma dessas categorias.

\section{CONHECIMENTO E INFORMAÇÃO}

Nesta primeira categoria de análise o desenvolvimento da autonomia correlaciona-se à escolha e ao desenvolvimento do conteúdo proposto, tanto por parte do/a professor/a quanto do/a aluno/a, para que, dessa forma, seja possível realizar uma reflexão crítica acerca do conteúdo desenvolvido. O papel do/a professor/a está em oportunizar esse conhecimento aos/às alunos/as (FREIRE, 1996).

Alguns elementos que constituem esta categoria foram destacados pelos/as professores/as entrevistados/as quando disseram que: propunham a reflexão sobre o conteúdo que estava sendo apresentado, de modo conceitual e prático; apresentavam o conteúdo de diferentes formas, sempre estimulando o debate e a tomada de decisão por parte dos/as alunos/as em relação ao que estava sendo desenvolvido, e faziam do diálogo uma constante nas suas aulas.

Importa referir a diferença entre os conceitos de conhecimento e informação, sendo o primeiro compreendido como algo construído a partir da reflexão sobre a realidade ou a partir da manifestação de outros sujeitos acerca do mesmo fenômeno (BOUFLEUER, 2017). Já a informação, está vinculada com aquilo que o/a aluno/a traz para o ambiente de sala de aula, a partir dos diferentes meios de comunicação, sem uma reflexão mais elaborada a respeito dela.

Outro fator que destacamos por estar presente na fala dos/as entrevistados/as é a necessidade de que o conteúdo que está sendo desenvolvido tenha significado para os/as alunos/as. Como ressalta a professora Alice, ao dizer que o/a aluno/a precisa ver sentido no que está sendo apresentado, se interessar por esse conhecimento e ter comprometimento com a sua participação em aula. O professor Elias também destaca que quanto mais o/a educando/a apropriar-se dos conteúdos, como, por exemplo, os esportivos, mais se sentirá à vontade para interagir com os/as outros/as nos diferentes lugares que frequenta.

Ainda sobre conhecimento, Freire (1996) argumenta que ensinar exige a consciência do inacabamento, de modo que o/a professor/a não pode ser visto/a como detentor/a exclusivo/a do conhecimento. O autor entende a educação como um processo horizontal e considera que os conhecimentos trazidos pelos/as alunos/as, a 
partir de suas experiências de vida, precisam ser valorizados e estimulados de modo que possam contribuir com a reflexão oriunda da realidade concreta do/a educando/a.

A escuta atenta, preconizada por Freire (1996), é um dos fundamentos do diálogo e, portanto, demanda a transformação das relações autoritárias e verticalizadas entre professores/as e alunos/as, em relações horizontalizadas, em que o/a professor/a fala com e não para os/as alunos/as. Saber escutar é uma atitude de respeito aos saberes e às experiências dos/das educandos/as.

Tal abertura à escuta e ao falar foi observada na fala da professora Alice, quando ela discorreu sobre a proposta de aula e o desenvolvimento dos conteúdos, dizendo que "[...] a gente escuta, tem que conversar, construir junto". Como manifesta o professor Heitor, quando trabalhamos o conhecimento a partir de um conteúdo que o/a aluno/a gosta, ele/a tem mais interesse por esse aprendizado. Porém, os professores Heitor e Marcos ressaltam um ponto importante, que está vinculado a não trabalhar apenas com aquilo que o/a aluno/a gosta ou já conhece, mas apresentar novos conhecimentos para que amplie a bagagem de saberes e possa ter autonomia para debater e para se posicionar em relação ao que está sendo discutido. É importante que esse conhecimento esteja associado a todas as questões que perfazem seu mundo, sejam elas de ordem cultural, econômica, política e/ou social, pois, conforme Freire (1996, p. 110), "a educação é uma forma de intervenção no mundo".

A problematização acerca dos conteúdos desenvolvidos nas aulas de EF foi evidenciada na fala do professor Augusto, ao mencionar que o ensino está para além do conhecimento sobre regras do jogo e ao relatar que, durante uma de suas aulas, dirigiuse aos/às alunos/as dizendo: "Gente... o futebol não é só 11 contra 11, o futebol envolve muitas outras coisas, envolve muitas outras questões relacionadas à mídia, relacionadas à relação entre as pessoas, relação entre os povos" (Professor Augusto).

É importante que os estudantes vivenciem, pratiquem, discutam e, sobretudo, compreendam os aspectos socioculturais inerentes às práticas corporais. A tematização crítica dos elementos que compõem a cultura corporal pode fornecer aos estudantes mais condições de compreender como é organizado o fenômeno esportivo e as suas características, as concepções de corpo, saúde e estética que a mídia propaga, as relações entre gênero e mercado de trabalho presentes no meio esportivo e na sociedade, entre outras. Todas essas questões podem fornecer subsídios para os estudantes agirem com autonomia em seu cotidiano (BOSCATTO; DARIDO, 2017, p. 103).

O professor lan ressaltou que "[...] ninguém consegue ser autônomo e nem tu consegues ajudar alguém a ser autônomo se essa pessoa não tem uma clareza das coisas que acontecem ao seu redor, se ela não tem a capacidade de enxergar o que tem na volta dela e interpretar - com o seu viés, é claro".

Para os/as professores/as Alice, Caio e Heitor, o vínculo entre professor/a e alunos/as é um fator determinante do processo de desenvolvimento da autonomia, pois quando os/as estudantes sentem-se mais próximos/as, confiam no/a professor/a, este/a passa a ter um papel de mediador/a do processo de produção do conhecimento que 
está em debate, como destacado pela professora Alice: "tu dá sugestões, tu dá encaminhamentos, tu dá ideias, tu dá conselhos para que elas consigam resolver...".

Ainda a respeito da necessidade da presença do diálogo durante os processos de ensino e de aprendizagem, torna-se necessário a proposição de debates em que todos/as os/as alunos/as tenham espaço para expor suas opiniões a respeito de diferentes temas. Freire (2011b) sublinha a importância de um diálogo crítico e libertador, de modo que os/as alunos/as sejam constantemente questionados/as. Durante a fala de um dos professores, foi possível observar a importância dada por ele ao ato de questionar os/as alunos/as: "Então, em todas as minhas aulas tem perguntas, todas, sem exceção. Aliás, eu dou poucas respostas, eu faço muitas perguntas" (Professor lan).

A professora Alice destacou que quando um/a aluno/a, ou a turma, está com dificuldade para compreender algum conteúdo, ela conversa com todos/as para que sintam-se mais confiantes e não desistam daquele aprendizado, bem como reforça a importância de que no grande grupo eles/as se ajudem. Entendemos que cabe ao/a professor/a incentivar o/a aluno/a na busca pelo aprendizado, pelo conhecimento, bem como de possibilitar que a sala de aula seja um lugar de constante troca, conversa e compartilhamento de experiências.

Para Freire (1996, p. 164), as práticas educativas dialógicas que têm como premissa o querer bem o/a educando/a demandam "um exercício constante em favor da produção e do desenvolvimento da autonomia de educadores e educandos". Para tanto, elas devem promover experiências que o/a aluno/a possa levar para o seu cotidiano, a fim de transformá-lo, como relata um dos professores: "fazer essa informação vir de dentro para fora neles e se transformar em ações efetivas" (Professor Manoel).

Para que as ações sejam efetivas, o conhecimento deve ser amplamente debatido e refletido de forma aprofundada e crítica, bem como estar relacionado com questões pessoais, sociais, culturais e políticas que circundam a realidade dos/as alunos/as. Destacamos então que, o desenvolvimento da autonomia do/a educando/a será estimulado se, nesse primeiro momento, o/a professor/a tiver conhecimento do conteúdo que está desenvolvendo, considerar os conhecimentos e as informações trazidas pelos/as estudantes, fomentar o diálogo e aproximar o conteúdo desenvolvido da realidade dos/as alunos/as.

\section{REFLEXÃO CRÍTICA}

Passamos à segunda categoria de análise, a criticidade, que na perspectiva freiriana "é a capacidade do educando e do educador refletirem criticamente a realidade na qual estão inseridos, possibilitando a constatação, o conhecimento e a intervenção para transformá-la" (MOREIRA, 2017, p. 97).

Nesse sentido, destacamos a compreensão do professor lan, que reforça a importância de o/a estudante observar, analisar e diagnosticar, refletir sobre o conhecimento que está sendo debatido para que se possa "interpretar e chegar a 
algumas conclusões, mesmo que parciais, ou então, nem que ele chegue a formular novas perguntas" (Professor lan).

Entretanto, o desenvolvimento da autonomia não se dá de forma rápida, tal como salienta o professor Luiz. Para ele, o/a aluno/a precisa de tempo para processar e construir o seu aprendizado, "[...] um tempo de aprendizado, um tempo de amadurecimento, sem queimar etapas" (Professor Luiz). A reflexão não é uma tarefa simples e demanda o respeito ao tempo do/a educando/a para que ele/a possa criar argumentos, formar uma opinião crítica sobre o conhecimento que está sendo discutido em aula.

Sobre a criticidade, Freire (1996) ressalta que a superação da ingenuidade se dá através do desenvolvimento da curiosidade dos/as educandos/as, de uma curiosidade epistemológica, inquietante e indagadora. O professor Manoel destacou que o/a aluno/a tem que refletir sobre as informações, "[...] tem que ter conhecimento sobre as coisas, tem que exercer a crítica sobre essa informação e sobre esse conhecimento". A fala do professor Manoel vai ao encontro do apontado por Freire (1996) sobre a importância do pensar sobre o fazer. O autor destaca: "[o] de que se precisa é possibilitar, que, voltandose sobre si mesma, através da reflexão sobre a prática, a curiosidade ingênua, percebendo-se como tal, se vá tornando crítica" (FREIRE, 1996, p. 43).

Entendemos que as práticas pedagógicas em EF são lugares de promoção do desenvolvimento da reflexão crítica do/a aluno/a, pois elas instigam a reflexão da e na prática, com vistas à transformação do meio em que está inserido/a. No entanto, tais práticas pedagógicas precisam ser contextualizadas para que possam produzir sentidos e significados ao aprendizado, reverberando no dia a dia dos/as alunos/as. Freire (1996, p. 76) ressalta que a aprendizagem é significativa quando ela possibilita "[...] transformar a realidade, para nela intervir, recriando-a".

Um exemplo de como o desenvolvimento da criticidade pode acontecer numa aula de EF foi evidenciado na fala do professor Augusto, quando ele diz buscar que a compreensão seja para além dos aspectos técnicos e táticos que envolvem o esporte. Para ele, é necessário "entender qual é a implicação do esporte enquanto fenômeno cultural' (Professor Augusto). Outro exemplo foi evidenciado pelo professor Luiz e está relacionado aos conteúdos de ginástica, de atividade física e saúde. De acordo com o professor Luiz, cabe à EF, no sentido do desenvolvimento da autonomia do/a aluno/a, despertar o gosto pela atividade física, que poderá contribuir para a constituição de um sujeito ativo em sua vida adulta.

A respeito dos valores, desenvolvidos através dos conteúdos atitudinais nas aulas de EF, o professor lan destacou que eles extrapolam o espaço-tempo da sala de aula, expandindo-se ao cotidiano dos/as estudantes. Nesse sentido, considerando que os/as alunos/as pertencem a uma determinada realidade, valores como respeito, cooperação, ajuda ao próximo, trabalho coletivo são imprescindíveis ao convívio coletivo.

Montiel et al. (2019, p. 9), tendo como base as obras de Freire que abordam o desenvolvimento de valores, da moral do/a educando/a, da ética, destacam que "[...] é possível pensar uma educação ética, pautada no respeito e cuidado com o outro, práticas essas potencializadas a partir de propostas educativas que vinculem o sensível 
com o cognitivo e com o motor". Para Freire (1996, p. 37), "[...] o ensino dos conteúdos não pode dar-se alheio à formação moral do educando".

Em relação ao trato com os conteúdos, Freire (1996) alerta sobre a necessidade de ultrapassarmos a curiosidade ingênua e avançarmos para uma curiosidade crítica. Para o autor, "[é] pensando criticamente a prática de hoje ou de ontem que se pode melhorar a próxima prática" (FREIRE, 1996, p. 44). O autor ainda destaca a importância do discurso teórico se aproximar da prática, pois quanto mais próximos os discursos forem, mais facilitada torna-se a reflexão crítica da realidade e a sua transformação.

Nesse sentido, o professor Igor salientou que as aulas de EF devem ter um misto de prática e teoria, como assevera: "[...] é importante eles conhecerem o movimento, mas é importante eles fazerem o movimento". Dessa forma, afirmamos que os/as professores/as de EF não devem apenas trabalhar com o aspecto motor, corporal, que envolve a área, mas fazer com que os/as alunos/as, ao experimentar os movimentos, reflitam conceitualmente sobre o conteúdo desenvolvido e se apropriem dele.

Freire (2011a) sublinha que é imprescindível o desenvolvimento da consciência crítica dos indivíduos para que os/as educandos/as possam chegar à autonomia e, consequentemente, intervir na sociedade e transformar suas realidades. A respeito da contribuição das aulas de EF para o desenvolvimento da consciência crítica, Montiel et al. $(2019$, p. 15) destacam que "[a]s práticas pedagógicas devem promover, a todo instante, a reflexão crítica do aluno, o refletir a partir da sua prática para compreender e, aí sim, modificar o meio em que está inserido".

\section{TOMADA DE DECISÃO}

O desenvolvimento da autonomia do/da educando/a se faz perante a possibilidade de tomada de decisões e da responsabilização por suas ações, ambas ponderadas pelo que melhor contribui para o coletivo. Tomada de decisão, última categoria de análise, tem a ver com ação-reflexão, entendida na perspectiva freiriana, como o direito de "decidir, de optar, de criar e recriar o mundo" (KRONBAUER, 2017, p. 24).

Os/as professores/as enfatizaram que o ato de o/a estudante fazer suas próprias escolhas e tomar decisões potencializa o desenvolvimento da sua autonomia, como exposto no fragmento a seguir:

Eu entendo que o aluno, ele possa conhecer as diversas coisas, os diversos temas, as diversas questóes da vida em geral. E que ele possa emitir uma opinião, para si mesmo, sobre isso para poder tomar as suas decisões. E que as decisóes dele não sejam tomadas pela opinião do outro, pela ação do outro, que ele seja capaz de gerenciar as próprias ações e tomar as próprias decisóes (Professora Helena). 
Nesse mesmo sentido, o professor Elias sinalizou que para o desenvolvimento da autonomia, o/a estudante deve saber "o que quer, o que pode fazer e como fazer" e, especificamente em relação à $E F$, que esse/a estudante tenha consciência de sua saúde, sua qualidade de vida, o que quer para si, para o seu corpo, de decidir se precisa ou não emagrecer, tonificar o corpo, realizar uma atividade física com regularidade, mudar hábitos alimentares, entre outros elementos que fazem parte dos conteúdos da EF.

No contexto das aulas de EF, a tomada de decisão é um fator bastante presente. Um dos conteúdos frequentemente desenvolvidos nas aulas são os esportivos, em especial os jogos. Esses são potentes estimuladores do desenvolvimento da autonomia. Para o professor Heitor, "[...] os jogos são tomada de decisão o tempo inteiro". Ainda em relação ao jogo, o professor Pedro destacou que o desenvolvimento da autonomia durante um jogo se faz quando o/a aluno/a "[...] em cima da situação que ele está vivenciando, tome a melhor escolha ou tome a escolha correta para a atividade dele, para que ele consiga atingir o objetivo dele, tenha o sucesso na escolha dele".

Freire (2011a, p. 41) destaca que é preciso criar "oportunidade para que os educandos sejam eles mesmos", a partir de uma educação que, ao invés de inibir e/ou restringir o/a aluno/a, amplie possibilidades de constituição de lugares de escuta e fala, bem como estimule a autonomia e a criatividade. A criatividade, a iniciativa e a independência foram evidenciadas pelos/as professores/as Flora, Helena e Heitor. A professora Flora comentou que um/a aluno/a é autônomo/a quando "[...] cria, toma decisões por ele".

Nesse mesmo sentido, o professor lan sinalizou que a autonomia se dá quando o/a aluno/a tem "condições de tomar a sua própria decisão e agir perante esse cenário, essas pessoas, e agir com propriedade". Já o professor Heitor enfatizou que, independente do acerto ou erro, o que importa é que os/as aluno/as tenham "[...] a capacidade de tomar decisão, independente se vão acertar a decisão ou errar".

Para o professor Caio, a autonomia está vinculada ao empoderamento, ao/à educando/a se sentir capaz de realizar determinada tarefa, destacando que é papel do/a professor/a fazer com que o/a aluno/a seja responsável por determinada tarefa e/ou ação em sala de aula, ou seja, "[...] tu empoderar ele em uma atividade, fazendo ele se sentir responsável por aquilo, se sentir útil por aquilo e saber que ele pode" (Professor Caio).

A tomada de decisões está muito vinculada ao fato de o/a aluno/a ter iniciativa, responsabilizar-se por ações no contexto de sala de aula, ser protagonista dos seus processos de ensino e de aprendizagem, conforme podemos observar na fala de uma das professoras, ao se referir à ação do/a aluno/a no contexto de aula: "[...] em algum momento tu vai ser o protagonista, em algum momento tu vai ter que decidir isso" (Professora Helena). Para Betti et al. (2014, p. 1634), desenvolver a "autonomia na EF exige elevar a capacidade crítica dos sujeitos para tomarem decisões, fazerem escolhas, agirem e se pronunciarem no mundo".

Os elementos aqui sinalizados correspondem ao preconizado por Freire (1996) sobre o ato de ensinar e o desenvolvimento da autonomia. Não obstante, Silva, Silva e Molina Neto (2016, p. 333), ao se referirem à potencialidade da EF na EPTNM, ressaltam que "[a] capacidade crítica e a autonomia do estudante a serem desenvolvidas pela 
Educação Física nos IFes vão além do mero 'exercitar-se', ou de fornecer 'dicas' técnicas sobre como manter o corpo saudável, ou produtivo, ao gosto do mercado de trabalho".

Dessa forma, reiteramos a importância da EF para a formação integral do ser humano e da importância de que os/as professores/as estejam compromissados/as com tal formação. Tal compromisso foi expresso na fala abaixo:

\begin{abstract}
Meu desejo é que o aluno melhore as possibilidades dele enquanto formação cidadã. Eu acho que a Educação Física pode contribuir muito para isso. Formação cidadã como um todo, que eles saiam daí para ser melhores pessoas para o mundo, se vejam enquanto esse cidadão crítico, atuante e tal. No geral é isso, eu acho que tem muito a ver com a formação integral(Professor Manoel).
\end{abstract}

A análise realizada evidenciou que as aulas de EF contribuem para desenvolver a autonomia dos/as alunos/as. Destacamos que as práticas educativas que promovam o desenvolvimento da autonomia do/a educando/a são imprescindíveis para a formação de sujeitos críticos, participativos e compromissados com a transformação da realidade.

\title{
CONCLUSÃO
}

A possibilidade do desenvolvimento de autonomia dos/as educandos/as, em aulas regulares de EF no EMI, segundo os/as professores/as de EF do IFSul, está vinculada ao processo que se inicia no compartilhamento dos conhecimentos e perpassa a reflexão crítica e a tomada de decisões, processo este que vai ao encontro do sinalizado por Freire ao longo de suas obras.

Entendemos que a EF apresenta grande potencial para o desenvolvimento da autonomia do/a educando/a, considerando as particularidades que envolvem esse componente curricular, tais como: o ambiente de sala de aula, que na maioria das vezes é totalmente diferente das demais disciplinas; a diversidade de práticas da cultura corporal desenvolvidas; a presença de elementos como criatividade, a tomada de decisão, o trabalho coletivo, a resolução de problemas, a comunicação e o pensamento crítico.

Reafirmamos, então, ser fundamental a presença da EF na EPTNM para que superemos a formação para o mercado de trabalho e consolidemos uma formação para o mundo do trabalho. Formação esta ocupada com o desenvolvimento integral dos sujeitos e compromissada com o desenvolvimento de pessoas críticas e atuantes na sociedade em que estão inseridas. Formação de cidadãos/ãs que possam enfrentar, resistir e romper com o sombrio e autoritário momento que vivemos no Brasil e em muitos lugares do mundo. 
MONTIEL, F. C.; JÚNIOR, A. J. R.; ANDRADE, D. M. de ${ }_{i}$ AFONSO, M. da R.

PAULO FREIRE AND AUTONOMY DEVELOPMENT IN THE INTEGRATED HIGH SCHOOL OF IFSUL: CONTRIBUTIONS FROM PHYSICAL EDUCATION

ABSTRACT: Based on Paulo Freire's thought, this study aimed to understand the possibilities of developing autonomy in regular classes of Physical Education in the Integrated High School of Instituto Federal Sul-rio-grandense. Thirteen Physical Education teachers with 6-15 years of work at the institution were interviewed. The Discursive Textual Analysis supported by NVivo was used to analyze data. Elements pointing out autonomy development in regular classes of Physical Education in the Integrated High School were identified through encouragement of knowledge sharing, critical reflection, and decision-making, thus evidencing the potentiality of Physical Education in Technical-Professional High School Education to engage and enable people to think critically.

KEYWORDS: High School. Professional Education. Physical Education. Autonomy.

PAULO FREIRE Y EL DESARROLLO DE LA AUTONOMIA EN LA ENSEÑANZA MEDIA INTEGRADA DEL IFSUL: CONTRIBUCIONES DE LA EDUCACIÓN FISICA

RESUMEN: El estudio tuvo como objetivo, a partir del pensamiento de Paulo Freire, comprender las posibilidades de desarrollar la autonomía en las clases regulares de Educación Física de la Enseñanza Media Integrada del Instituto Federal de Rio Grande do Sul. Fueron entrevistados/as 13 profesores/as de Educación Física, con vinculo institucional entre 6 y 15 años. Se recurrió al Análisis Textual Discursivo, con soporte del NVivo, para analizar los datos. Se identificaron elementos que señalan la presencia del desarrollo de la autonomía en las clases regulares de Educación Física en la Enseñanza Media Integrada al incentivar el intercambio de conocimientos, la reflexión crítica y la toma de decisiones, evidenciando la potencialidad de la Educación Física para la formación de personas críticas y participativas en la Educación Profesional Técnica de Nivel Medio.

PALABRAS CLAVE: Enseñanza Media; Educación Profesional. Educación Física. Autonomía.

\section{REFERÊNCIAS}

BETTI, M.; KNIJNIK, J.; VENÂNCIO, L. V.; NETO, L. S.; DAOLIO, J. Fundamentos filosóficos e antropológicos da Teoria do Se-movimentar e a formação de sujeitos emancipados, autônomos e críticos: o exemplo do currículo de Educação Física do Estado de São Paulo. Movimento, Porto Alegre, v. 20, n. 4, p. 1631-1653, out/dez., 2014. Disponível em: <https://doi.org/10.22456/1982-8918.46732>. Acesso em: 28 maio 2019.

BICUDO, M. A. V. (org.). Pesquisa qualitativa segundo a visão fenomenológica. São Paulo: Cortez, 2011. 
BOSCATTO, J. D.; DARIDO, S. C. A Educação Física no Ensino Médio Integrado à Educação Profissional e Tecnológica: percepções curriculares. Revista Pensar a Prática, Goiânia, v. 20, n. 1, jan./mar., p. 99-111, 2017. Disponível em: <https://www.revistas.ufg.br/fef/article/view/39029>. Acesso em: 28 maio 2019.

BOUFLEUER, J. P. Conhecer/Conhecimento. In: STRECK, D. R.; REDIN, E.; ZITKOSKI, J. J. (org.). Dicionário Paulo Freire. 3. ed. Belo Horizonte: Autêntica Editora, 2017. p. 85-86.

BRASIL. Lei no 9.394, de 20 de dezembro de 1996. Estabelece as diretrizes e bases da educação nacional. Brasília: Ministério da Educação, 1996. Disponível em: <http://www.planalto.gov.br/ccivil_03/leis/l9394.htm>. Acesso em: 9 jun. 2019.

BRITO, D. S.; CALDAS, F. S. A evolução da carreira de magistério de ensino básico, técnico e tecnológico (EBTT) nos Institutos Federais. Revista Brasileira de Educação Profissional Tecnológica, Natal, v. 1, n. 10, p. 85-96, 2016. Disponível em: <https://doi.org/10.15628/rbept.2016.4024>. Acesso em: 10 out. 2018.

CIAVATTA, M. A formação integrada: a escola e o trabalho como lugares de memória e de identidade. In: FRIGOTTO, G.; CIAVATTA, M.; RAMOS, M. (org.). Ensino médio integrado: concepção e contradições. São Paulo: Cortez, 2015. p. 83-106.

CONIF. Conselho Nacional das Instituições da Rede Federal de Educação Profissional, Científica e Tecnológica. Histórico. Disponível em: <http://portal.conif.org.br/br/redefederal/historico-do-conif>. Acesso em: 24 mar. 2019.

FREIRE, P. Educação e mudança. 34. ed. São Paulo: Paz e Terra, 2011 a.

FREIRE, P. Pedagogia da autonomia: saberes necessários à prática educativa. São Paulo: Paz e Terra, 1996.

FREIRE, P. Pedagogia da esperança: um reencontro com a pedagogia do oprimido. 24. ed. Rio de Janeiro: Paz e Terra, 2018.

FREIRE, P. Pedagogia do oprimido. 50. ed. Rio de Janeiro: Paz e Terra, 2011b.

IFSUL. Instituto Federal de Educação, Ciência e Tecnologia Sul-rio-grandense. Projeto Pedagógico Institucional. 2015. Disponível em: <http://www.ifsul.edu.br/projetopedagogico-istitucional >. Acesso em: 23 mar. 2019.

ISAIA, S. M.; BOLZAN, D. Compreendendo os movimentos construtivos da docência superior: construções sobre pedagogia universitária. Linhas Críticas, Brasília, v. 14, n. 26, p. 25-42, 2008. Disponível em: <https://doi.org/10.26512/lc.v14i26.3424>. Acesso em: 22 ago. 2018. 
MONTIEL, F. C.; JÚNIOR, A. J. R.; ANDRADE, D. M. de; AFONSO, M. da R.

KRONBAUER, L. G. Ação-reflexão. In: STRECK, D. R.; REDIN, E.; ZITKOSKI, J. J. (org.). Dicionário Paulo Freire. 3. ed. Belo Horizonte: Autêntica Editora, 2017. p. 23-24.

MONTIEL, F. C. A Educação Física no Instituto Federal Sul-rio-grandense: desenvolvimento da autonomia do(a) educando(a). Orientadora: Mariângela da Rosa Afonso. 2019. 199 p. Tese (Doutorado em Educação Física) - Escola Superior de Educação Física, Universidade Federal de Pelotas, Pelotas, 2019.

MONTIEL, F. C.; PORTO, L. B. Para além das habilidades motoras nas aulas de Educação Física no Ensino Médio. CCNExt - Revista de Extensão, Santa Maria, v. 3, p. 1128-1133, $2016 . \quad$ Disponível em: $<$ http://coral.ufsm.br/revistaccne/index.php/ccnext/article/viewFile/1178/869 $>$. Acesso em: 15 mar. 2019.

MONTIEL, F. C.; SILVA, P. R. L. Uma criação cooperativa pensando na preservação do Meio Ambiente. Revista Didática Sistêmica, Rio Grande, v. 16, n. 1, 2014. Disponível em: https://periodicos.furg.br/redsis/article/view/5232. Acesso em: 15 mar. 2019.

MONTIEL, F. C.; AFONSO, M. R.; SANTOS, L. L., SILVA, P. R. L. Ética, autonomia e pensamento crítico nas aulas de Educação Física no ensino médio. Motrivivência, Florianópolis, v. 31, n. 58, p. 1-21, maio 2019. Disponível em: <https://doi.org/10.5007/2175-8042.2019e56991>. Acesso em: 02 abr. 2020.

MORAES, R.; GALIAZZI, M. C. Análise textual discursiva. 2. ed. Ijuí: Editora Unijuí, 2011.

MORAIS, J. K. C.; HENRIQUE, A. L. S. O professor licenciado na educação profissional: quais os saberes docentes que alicerçam seu trabalho? Revista Brasileira de Educação Profissional Tecnológica, Natal, v. 1, n. 7, p. 66-74, 2014. Disponível em: $<$ https://doi.org/10.15628/rbept.2014.3499>. Acesso em: 12 abr. 2019.

MOREIRA, C. E. Criticidade. In: STRECK, D. R.; REDIN, E.; ZITKOSKI, J. J. (org.). Dicionário Paulo Freire. 3. ed. Belo Horizonte: Autêntica Editora, 2017. p. 97-98.

PITANO, S. C.; GHIGGI, G. Autoridade e liberdade na práxis educativa: Paulo Freire e o conceito de autonomia. Saberes: Revista interdisciplinar de Filosofia e Educação, Natal, v. 2, n. 3, 1 out. 2010. Disponível em: $<$ https://periodicos.ufrn.br/saberes/article/view/578/527>. Acesso em: 26 ago. 2019.

ROSSETTO JUNIOR, A. J. Projeto Rede Multiplicadores de Esporte Educacional. In: ROSSETTO JUNIOR, A. J. et al. Esporte educacional: a experiência do Centro de Referência Esportiva de Rio Grande. Florianópolis: Insular, 2015. p. 21-65.

SILVA, P. F.; MELO, S. D. G. O trabalho docente nos Institutos Federais no contexto de expansão da educação superior. Educação e Pesquisa, São Paulo, v. 44, p.1-18, 2018. 
Disponível em: <https://doi.org/10.1590/s1678-4634201844177066>. Acesso em: 12 abr. 2019.

SILVA, M. A.; SILVA, L. O.; MOLINA NETO, V. Possibilidades da Educação Física no Ensino Médio Técnico. Movimento, Porto Alegre, v. 22, n. 1, 2016. Disponível em: <https://seer.ufrgs.br/Movimento/article/view/54333>. Acesso em: 15 maio 2019.

SOARES, C. L.; TAFFAREL, C. N. Z.; VARJAL, E; CASTELLANI FILHO, L.; ESCOBAR, M. O.; BRACHT, V. Metodologia do ensino de Educação Física. São Paulo: Cortez, 1992.

SOBRINHO, E. M. A.; AZEVEDO, R. O. M.; STEFANUTO, V. A. Contribuições da Educação Física à formação humana integral no Ensino Médio Integrado. Educação Profissional e Tecnológica em Revista, Vitória, v. 2, n. 2, p. 118-132, 2018. Disponível em: <https://doi.org/10.36524/profept.v2i2.429>. Acesso em: 23 maio 2019.

YIN, R. K. Estudo de caso: planejamento e métodos. Tradução: Christhian Matheus Herrera. 5. ed. Porto Alegre: Bookman, 2015.

Fabiana Celente Montiel: Possui graduação em Licenciatura Plena em Educação Física pela Universidade Federal de Pelotas (2005), mestrado em Educação Física pela Universidade Federal de Pelotas (2010) e doutorado em Educação Física pela Universidade Federal de Pelotas (2019). Atualmente é membro do grupo de pesquisa GPEFE da Universidade Federal de Pelotas, professora do ensino médio, técnico e tecnológico do Instituto Federal Sul-rio-grandense - Campus Pelotas e professora do curso de Especialização em Esporte Escolar do Instituto Federal Sul-rio-grandense.

Orcid: https://orcid.org/0000-0002-9921-6703

E-mail: fabianamontiel@ifsul.edu.br

AdriAno José Rossetto JúniOR: Graduação em Educação Física - Uni-FMU - 1993, Pós-graduação em Educação Física Escolar - Uni-FMU - 2001, Mestrado em Educação: História, Política e Sociedade pela Pontifícia Universidade Católica de São Paulo (PUC-SP, 2003) e Doutorado em Ciências Sociais pela Pontifícia Universidade Católica de São Paulo - 2016, com pesquisa sobre os nexos do esporte, política e sociedade. É Coordenador Pedagógico da OSCIP - Instituto Esporte \& Educação - e Coordenador e professor dos Cursos de Pós-graduação em Educação Física escolar do Complexo Educacional-Fmu e Universidade Estácio de Sá.

Orcid: https://orcid.org/0000-0001-6423-877X

E-mail: adrianorossettojr@gmail.com 
MONTIEL, F. C.; JÚNIOR, A. J. R.; ANDRADE, D. M. de $;$ AFONSO, M. da R.

Danielle Müller de Andrade: Doutora em Educação Ambiental pelo PPGEAJFURG. Mestre em Educação Física pela ESEF/UFPel. Especialista em Educação Física, Corpo e Qualidade de Vida pela ESEF/UFPel. Graduada em Licenciatura Plena em Educação Física pela ESEF/UFPel. Docente do IFSul. Pesquisadora do srupo CEAMECIMComunidades Aprendentes em Educação Ambiental, Ciências e Matemática.

Orcid: https://orcid.org/0000-0002-4952-7570

E-mail: danielleandrade@ifsul.edu.br

MariÂngela da Rosa Afonso: Atualmente é professora titular da Universidade Federal de Pelotas. Possui graduação em Licenciatura em Educação Física pela Universidade Federal de Pelotas (1985), mestrado em Educação Física pela Universidade Gama Filho (1992) e doutorado em Educação pela Universidade Federal do Rio Grande do Sul (2003). É tutora do PET (Programa Educação Tutorial) da ESEF/UFPel, desde 2018.

Orcid: https://orcid.org/0000-0002-8853-719X

E-mail:mrafonso.ufpel@gmail.com

Este periódico utiliza a licença Creative Commons Attribution 3.0, para periódicos de acesso aberto (Open Archives Initiative - OAI). 